\title{
LAMBERT W FUNCTION BASED SEMI-ANALYTICAL FRAMEWORK FOR ESTIMATION OF SPEED AND PASSENGER CAR UNIT
}

\author{
SUBHADIP BISWAS ${ }^{1}$, SATISH CHANDRA ${ }^{2} \&$ INDRAJIT GHOSH $^{3}$ \\ ${ }^{1}$ Research Scholar, Department of Civil Engineering, Indian Institute of Technology Roorkee, India \\ ${ }^{2}$ Director, CSIR - Central Road Research Institute, India \\ ${ }^{3}$ Assistant Professor, Department of Civil Engineering, Indian Institute of Technology Roorkee, India
}

\begin{abstract}
Use of speed prediction model is multi-faceted and widely acknowledged in various aspects of Traffic Engineering. However, developing speed model is a challenging task particularly in the context of urban mixed traffic where vehicles possessing diverse static and dynamic characteristics use the same carriageway without any segregation. Here the traffic composition plays a vital role in determining the vehicular speed. Thus, the present study aims to develop a volume based speed model which will also afford the opportunity to monitor the individual influences of different vehicle categories present in the traffic stream. Classified traffic volume and speed data have been collected from different mid-block locations on two lane undivided urban roads. A novel Lambert W function based framework has been proposed in this work to model individual speed in a mixed traffic stream. Validation results affirm the accuracy of the model since a good agreement has been observed between the speeds observed and the speeds predicted by the model developed. Determination of Passenger Car Unit (PCU) also requires speed information of individual vehicle types. Therefore, the predicted speeds by the model developed have been utilized in estimation of PCU for individual vehicle type. Sensitivity analysis has been performed in order to observe the influences of traffic volume and its composition on speed and as well as PCU of individual vehicles.
\end{abstract}

Keywords: speed, traffic volume, PCU, Lambert W, macroscopic traffic flow model, mixed traffic.

\section{INTRODUCTION}

Speed on an urban corridor replicates its performance by mobility approach. Speed information are required in examining the road consistency as well as the driver expectancy on the road. Requirement of speed data is also crucial in case of safety assessment [1], pollution study [2] or congestion modelling [3]. However, the collection of speed data in the field is laborious, often infeasible and even sometimes collected data cannot fulfil designer's requirements. All these issues involved in field data collection have motivated researchers to emphasize on mathematical models which can predict the speed against given condition(s). Although many of these models highlight the influences of road geometry [4], weather condition [5] and side frictional elements [6] on speed, prime focus has always been embedded towards the speed-volume relationship. A good amount of research conducted till now, has led to develop numerous speed-volume models [7], [8]. All these research outcomes however, could not saturate the need due to ever changing vehicle characteristics. On the other hand, it is more challenging to develop speed models in the context of developing countries where flow of traffic on urban roads is characterized by a high degree of heterogeneity. Vehicles with a wide range of static and dynamic characteristics use the same right-of-way without any segregation. Being different in size, vehicles use to take any suitable lateral gap left empty by other vehicles across the carriageway resulting in poor lane discipline. Further, it is quite obvious that the presence of individual vehicle category would have different influences on stream speed. Therefore, for the mixed traffic conditions, there 
is a need to develop speed model which would also provide the opportunity to monitor the influences of individual vehicle categories present in the traffic stream.

Passenger Car Unit (PCU) or Passenger Car Equivalent (PCE) is required while converting mixed traffic flow to its equivalent homogeneous. PCU was first conceptualized in Highway Capacity Manual (HCM) 1965 [9] and was defined as "the number of passenger cars that will result in the same operational conditions as a single heavy vehicle of a particular type under specified roadway, traffic and control conditions". For heterogeneous traffic conditions, adopting PCU values recommended in HCM or capacity manuals of other developed nations could be infeasible due to high dissimilarities in vehicular and driving characteristics [10]. Therefore, a significant volume of research [11], [12] has been devoted till date to determine PCU values which are compatible to mixed traffic conditions. Also, many of them have come to a common agreement that PCU should be dynamic as it varies depending upon traffic and other characteristics. Concentrating on traffic circumstance, the change in traffic volume and its composition leads to variation in speed so as in PCU of individual vehicle categories. On this background, objective of the present study is to estimate speed and PCU of individual vehicle categories considering the influences of traffic volume and its composition in the context of urban mixed traffic.

\section{RESEARCH METHODOLOGY}

Methodology adopted to achieve the aforementioned objective completes in two primary parts: 'the estimation of speed' and 'the estimation of PCU'. 'The estimation of speed' part involves the application of Lambert $\mathrm{W}$ function. Therefore, a brief demonstration of this function has been placed in the first section before describing the methodology.

\subsection{Lambert $\mathrm{W}$ function}

Suppose, two variables $\mathrm{x}$ and $\mathrm{z}$ be related as:

$$
\mathrm{xe}^{\mathrm{x}}=\mathrm{z} \text {, }
$$

Euler [13] introduced a function in solving the eqn 1 and represented it as:

$$
\mathrm{x}=\mathrm{W}(\mathrm{z}) \text {, }
$$

Since the work by Euler was an extension of the pioneer work of Lambert who had found a solution of the trinomial equation $x=q+x^{m}$, the function $\mathrm{W}$ was named as Lambert $\mathrm{W}$ in his honour. $\mathrm{W}(\mathrm{z})$ can be computed as:

$$
W(z)=\sum_{n=1}^{\infty} \frac{(-n)^{n-1}}{n !} z^{n}
$$

Lambert $\mathrm{W}$ function has two branches: the principal branch $(\mathrm{W}(\mathrm{z})>-1)$ and the minor branch $(W(z)<-1)$. Thefunction changes its branch at the point $(-1 / e,-1)$ as shown in Fig. 1.

Further it is quite interesting to see how $W(z)$ changes for $-1 / e<z<0$. Within this specified range of $z, W(z)$ is double valued while it is single valued for $z>0$ and $z=-e-1$. It is also a notable fact that $\mathrm{W}(\mathrm{z})$ cannot be computed for $\mathrm{z} \rightarrow 0$ by general iteration approach.

\subsection{Formulation of speed model: application of Lambert $\mathrm{W}$ function}

Greenberg [7], and Underwood [8], models are among the most fundamental macroscopic traffic flow models commonly used in traffic stream modelling. Expressions of Greenberg and Underwood models are presented in eqn (4) and eqn (5) respectively 


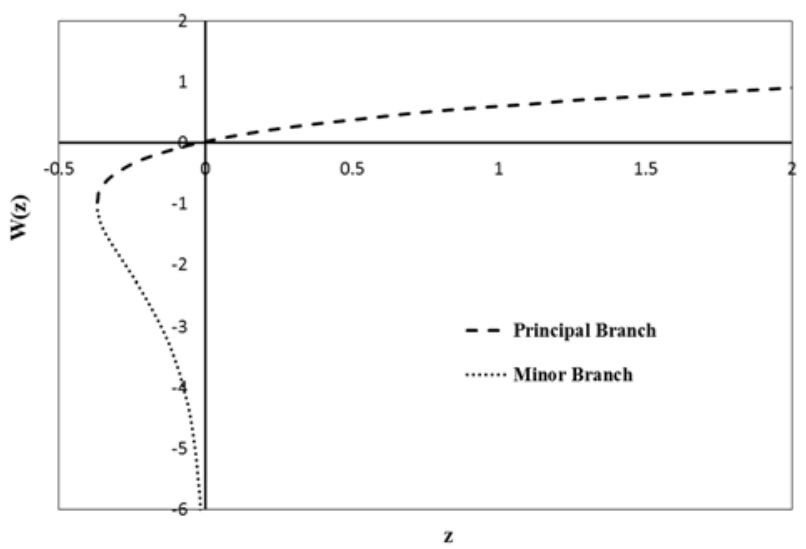

Figure 1: Schematic diagram representing two branches of Lambert $\mathrm{W}$ function.

$$
\begin{aligned}
& \mathrm{v}=\mathrm{v}_{0} \ln \left(\frac{\mathrm{k}_{\mathrm{j}}}{\mathrm{k}}\right) \\
& \mathrm{v}=\mathrm{v}_{\mathrm{f}} \mathrm{e}^{\left(-\frac{\mathrm{k}}{\mathrm{k}_{0}}\right)}
\end{aligned}
$$

$\mathrm{v}, \mathrm{v}_{\mathrm{f}}$ and $\mathrm{v}_{0}$ respectively are the average speed, free flow speed and the speed corresponding to the capacity. Similarly, $\mathrm{k}, \mathrm{k}_{\mathrm{j}}$ and $\mathrm{k}_{0}$ are the respective average density, jam density and the density corresponding to the capacity. Speed-volume model is more useful in average speed prediction since field measurement of volume $(\mathrm{q})$ is more feasible compared to that of density $(\mathrm{k})$. Therefore, both of these models need to be restructured based on the fundamental relation (eqn (6)).

$$
\mathrm{v}=\mathrm{v}_{0} \ln \left(\frac{\mathrm{k}_{\mathrm{j}}}{\mathrm{k}}\right) \mathrm{v}=\mathrm{v}_{\mathrm{f}} \mathrm{e}^{\left(-\frac{\mathrm{k}}{\mathrm{k}_{0}}\right)} \mathrm{q}=\mathrm{k} * \mathrm{v}
$$

Greenberg model (eqn (4)) is reformed as:

$$
\mathrm{q}=\mathrm{k}_{\mathrm{j}} \mathrm{v} \mathrm{e}^{-\left(\frac{\mathrm{v}}{\mathrm{v}_{0}}\right)}
$$

Now with the aim to develop a volume based speed prediction model, it is necessary to express speed (v) in terms of volume (q). However, there is no simple approach for finding the root of eqn (7). Let assume:

$$
-\frac{\mathrm{v}}{\mathrm{v}_{0}}=\mathrm{x} \quad \text { and } \quad-\frac{\mathrm{q}}{\mathrm{k}_{\mathrm{j}} \mathrm{v}_{0}}=\mathrm{y}
$$

Eqn (7) can be rewritten as:

$$
y=x e^{x}
$$

Using Lambert W function:

$$
\mathrm{x}=\mathrm{W}(\mathrm{y})
$$

Substituting $\mathrm{x}$ and $\mathrm{y}$ :

$$
\mathrm{v}=-\mathrm{v}_{0} \mathrm{~W}\left(-\frac{\mathrm{q}}{\mathrm{k}_{\mathrm{j}} \mathrm{v}_{0}}\right)
$$

However, the present study further aims to extend this model to vehicle category level so that it would yield the individual influences of different vehicle categories making the model 
compatible to mixed traffic conditions. It is presumed that vehicles belonging to different categories would have diverse influences on speed and therefore eqn (11) is modified as:

$$
\mathrm{v}_{\mathrm{j}}=-\mathrm{v}_{0} \prod_{\mathrm{i}} \mathrm{W}\left(-\frac{q_{i}}{\mathrm{k}_{\mathrm{j}}^{\mathrm{i}} \mathrm{v}_{0}^{\mathrm{i}}}\right)
$$

Now, the practical determination of the parameters $\mathrm{k}_{\mathrm{j}}^{\mathrm{i}}$ and $\mathrm{v}_{0}{ }^{\mathrm{i}}$ is difficult in the field. Due to this reason, in the present study, a parameter $\mathrm{a}_{\mathrm{i}}$ is introduced and Equation 12 is rewritten as:

$$
\mathrm{v}_{\mathrm{j}}=\mathrm{a}_{0} \prod_{\mathrm{i}}\left\{\mathrm{W}\left(\mathrm{q}_{\mathrm{i}}\right)\right\}^{\mathrm{a}_{\mathrm{i}}}
$$

Eqn (13) describes the influence of individual vehicle category ' $i$ ' on speed and qi denotes the hourly volume of that particular category. $a_{0}$ and $a_{i}$ are the constants which need to be evaluated. $a_{i}$ signifies the weightage of the vehicle category ' $i$ ' in influencing the speed of category ' $\mathrm{j}$ '. It is hypothesised that the parameter $\mathrm{a}_{\mathrm{i}}$ takes care of the terms $\mathrm{kj}_{\mathrm{j}}^{\mathrm{i}}$ and $\mathrm{v}_{0}{ }^{\mathrm{i}}$ along with effect of vehicle proportion. Having said so, the coefficients $\mathrm{a}_{\mathrm{i}}$ still need to be determined. To this end, the logarithm of both side of eqn (13) is taken and conventional least square minimization technique is used to determine the coefficients.

Similar modification is implemented upon Underwood model also. At first, the model (Equation 5) is reformed as:

$$
\mathrm{q}=-\mathrm{k}_{0} \mathrm{v} \ln \left(\frac{\mathrm{v}}{\mathrm{v}_{\mathrm{f}}}\right)
$$

Let's assume:

$$
\frac{\mathrm{v}}{\mathrm{v}_{\mathrm{f}}}=\mathrm{x} \quad \text { and } \quad-\frac{\mathrm{q}}{\mathrm{k}_{0} \mathrm{v}_{\mathrm{f}}}=\mathrm{y}
$$

Eqn (14) can be rewritten as:

$$
y=x \ln (x)
$$

Using Lambert W function,

$$
\mathrm{x}=\frac{y}{\mathrm{w}(\mathrm{y})}
$$

Derivation to the present form (eqn (17)) has been demonstrated in Appendix 1. Adopting the technique similar to previous case, the study arrives at the final model

$$
\mathrm{v}_{\mathrm{j}}=\mathrm{b}_{0} \prod_{\mathrm{i}}\left\{\frac{\mathrm{q}_{\mathrm{i}}}{\mathrm{W}\left(\mathrm{q}_{\mathrm{i}}\right)}\right\}^{\mathrm{b}_{\mathrm{i}}}
$$

$b_{0}$ and $b_{i}$ are the constants which need to be evaluated. $b_{i}$ signifies the weightage of the vehicle category ' $i$ ' in influencing the speed of category ' $j$ '. Thus, two classified volume-based speed models, eqn (13) and eqn (18) were formulated respectively from two existing traffic flow theories namely, Greenberg and Underwood models. To determine the coefficients in both of the equations, regression technique was adopted in the present study. Besides, it is also a notable fact that being volume (q) a positive number, W(q) always lie within the principal branch of the Lambert $\mathrm{W}$ function as per Fig. 1.

\subsection{Methodology for estimation of PCU}

On an urban road, speed can be a good performance measurer as it replicates the operating condition on the road by mobility approach. Among few other advantages of conceiving 'speed' as a PCU estimator, speed is accurately assessable on field and clearly perceived by 
other road users. These are the reasons behind a number of studies that have taken speed into consideration while estimating PCU [14], [15]. However, in a mixed traffic situation with poor lane discipline, vehicles take any lateral position across the carriageway left empty by other vehicles and move. Size of a vehicle thus plays a vital role in this situation in governing its performance. For instance, motorized two wheelers being small sized can accept smaller lateral gaps ahead while manoeuvring. As a result, they face less interruption even at a moderate congestion compared to other vehicle categories. This ability stipulates for a smaller equivalence factor for two-wheeler. Thus, speed without considering any dimensional factors of vehicles cannot be a good surrogate measure of interaction among vehicles specifically for highly heterogeneous traffic. With this background, the present study adopted the PCU model suggested by Chandra and Kumar [11] where vehicular speed as well as its projected rectangular area were judiciously taken into account to model PCU as given in eqn (19)

$$
\mathrm{PCU}_{\mathrm{i}}=\frac{\left(\mathrm{V}_{\mathrm{c}} / \mathrm{V}_{\mathrm{i}}\right)}{\left({ }_{\mathrm{c}} / \mathrm{A}_{\mathrm{i}}\right)}
$$

$P C U_{i}$ denotes the passenger car unit of vehicle type ' 1 '. $V_{c}$ and $A_{c}$ are the speed and the projected rectangular area of passenger car respectively. Similarly, $V_{i}$ and $A_{i}$ are the speed and the projected rectangular area of vehicle category 'i' respectively. Speeds in Equation 15 were obtained utilizing the speed models suggested in previous step whereas projected rectangular areas were taken by field measurement.

\section{FIELD DATA COLLECTION}

Traffic speed and volume data were collected from two mid-block locations on urban roads in Chandigarh, India. Both of these sections are two lanes undivided with similar road geometry. Few criteria were carefully considered while selecting a section for data collection purpose. The section should be:

- $\quad$ straight with no grade

- free from any on-street parking, bus stop or pedestrian cross-flow in the vicinity of the section ensuring minimal side frictional effect on vehicle movements

- $\quad$ situated away from the influence of upstream/downstream intersections

A $30 \mathrm{~m}$ of road length was selected and marked in each location. The vehicular movements on this selected road segment were then captured adopting the videography technique. A video recorder was attached on top of a 15 feet tall stand and this total set up was placed beside the road such a way that it would clearly capture the entire selected road segment. A total of 5 hours video was recorded at each of the selected location on a weekday with normal weather condition. Videography was followed by the data extraction through playing the video files on a computer screen. As a part of extraction, volume was measured by counting the number of vehicles crossing the section. Speed of individual vehicle was measured from the entry and exit time on the segment with an accuracy of $1 / 25 \mathrm{sec}$. All vehicles present in the traffic stream were divided into five categories: small car (CS), big car (CB), heavy vehicle (HV), motorized three-wheeler ( $3 \mathrm{~W})$ and motorized two-wheeler $(2 \mathrm{~W})$. All larger sized new generation cars (including SUV) with engine of more than $2500 \mathrm{cc}$ were considered as big car and the rest of all cars were taken under the small car category. Heavy vehicle category includes the larger sized vehicles like buses and trucks. For the estimation of PCU, small car category was selected as the standard vehicle category. Projected rectangular areas of all these categories were measured in the field and the same are given in Table 1. 
Table 1: Vehicle categories and their sizes.

\begin{tabular}{|l|c|c|c|c|c|}
\hline Vehicle Types & Small car & Big car & Heavy vehicle & Three-wheeler & Two-wheeler \\
\hline $\begin{array}{l}\text { Projected } \\
\text { Rectangular } \\
\text { Area }\left(\mathrm{m}^{2}\right)\end{array}$ & 5.36 & 8.11 & 24.54 & 4.48 & 1.20 \\
\hline
\end{tabular}

Traffic volume and average speed of individual vehicle category were thus taken from field data for each 5-min interval. A total of 129 data sets were formed among which $15 \%$ of the data were randomly selected and kept aside for validation purpose and the rest were utilized in developing the model.

\section{ANALYSIS AND RESULTS}

\subsection{Development of simultaneous speed models for individual vehicle categories}

In absence of considerable side frictional elements, speed on an urban road is completely governed by the characteristics of traffic volume and its composition. Classified traffic volumes, the parameters which can represent the total traffic volume as well as its composition characteristic, were suitably chosen as the design variables. Average speed of a vehicle category was considered as a function of hourly volumes of the five vehicle categories observed in the study. Eqn 13 and eqn 18 are rewritten as:

$$
\begin{gathered}
\mathrm{v}_{\mathrm{i}}=\mathrm{a}_{0} \times\left\{\mathrm{W}\left(\mathrm{q}_{\mathrm{cs}}\right)\right\}^{\mathrm{a}_{1}} \times\left\{\mathrm{W}\left(\mathrm{q}_{\mathrm{cb}}\right)\right\}^{\mathrm{a}_{2}} \times\left\{\mathrm{W}\left(\mathrm{q}_{\mathrm{hv}}\right)\right\}^{\mathrm{a}_{3}} \times\left\{\mathrm{W}\left(\mathrm{q}_{3 \mathrm{w}}\right)\right\}^{\mathrm{a}_{4}} \times\left\{\mathrm{W}\left(\mathrm{q}_{2 \mathrm{w}}\right)\right\}^{\mathrm{a}_{5}} \\
\mathrm{v}_{\mathrm{i}}=\mathrm{b}_{0} \times\left\{\frac{\mathrm{q}_{\mathrm{cs}}}{\mathrm{w}\left(\mathrm{q}_{\mathrm{cs}}\right)}\right\}^{\mathrm{b}_{1}} \times\left\{\frac{\mathrm{q}_{\mathrm{cb}}}{\mathrm{w}\left(\mathrm{q}_{\mathrm{cb}}\right)}\right\}^{\mathrm{b}_{2}} \times\left\{\frac{\mathrm{q}_{\mathrm{hv}}}{\mathrm{w}\left(\mathrm{q}_{\mathrm{hv}}\right)}\right\}^{\mathrm{b}_{3}} \times\left\{\frac{\mathrm{q}_{3 \mathrm{w}}}{\mathrm{w}\left(\mathrm{q}_{3 \mathrm{w}}\right)}\right\}^{\mathrm{b}_{4}} \times\left\{\frac{\mathrm{q}_{2 \mathrm{w}}}{\mathrm{w}\left(\mathrm{q}_{2 \mathrm{w}}\right)}\right\}^{\mathrm{b}_{5}}
\end{gathered}
$$

$\mathrm{v}_{\mathrm{i}}$ is the average speed of vehicle category ' $\mathrm{i}$ '. $\mathrm{q}_{\mathrm{cs}}, \mathrm{q}_{\mathrm{cb}}, \mathrm{q}_{\mathrm{hv}}, \mathrm{q}_{3 \mathrm{w}}$ and $\mathrm{q}_{2 \mathrm{w}}$ are the respective hourly volumes of small car, big car, heavy vehicle, three-wheeler and two-wheeler. Data sets comprised of classified volumes and corresponding average speeds were fitted into both of these equations (eqn 20 and eqn 21) separately and the unknown coefficients, $a_{i}$ and $b_{i}$ were determined by exercising the regression technique. Thus, two groups of speed prediction models (one based on Greenberg model; another on Underwood model) for individual vehicle categories were developed as given in eqns (22)-(31).

a) Model A: Speed prediction models based on Greenberg approach

$$
\begin{aligned}
& \mathrm{v}_{\mathrm{cs}}=5.172 \times\left\{\mathrm{W}\left(\mathrm{q}_{\mathrm{cs}}\right)\right\}^{0.475} \times\left\{\mathrm{W}\left(\mathrm{q}_{\mathrm{cb}}\right)\right\}^{-0.023} \times\left\{\mathrm{W}\left(\mathrm{q}_{\mathrm{hv}}\right)\right\}^{-0.066} \times\left\{\mathrm{W}\left(\mathrm{q}_{3 \mathrm{w}}\right)\right\}^{-0.227} \times \\
&\left\{\mathrm{W}\left(\mathrm{q}_{2 \mathrm{w}}\right)\right\}^{-1.076} \\
& \mathrm{v}_{\mathrm{cb}}=5.384 \times\left\{\mathrm{W}\left(\mathrm{q}_{\mathrm{cs}}\right)\right\}^{0.623} \times\left\{\mathrm{W}\left(\mathrm{q}_{\mathrm{cb}}\right)\right\}^{0.066} \times\left\{\mathrm{W}\left(\mathrm{q}_{\mathrm{hv}}\right)\right\}^{-0.130} \times\left\{\mathrm{W}\left(\mathrm{q}_{3 \mathrm{w}}\right)\right\}^{-0.234} \times \\
&\left\{\mathrm{W}\left(\mathrm{q}_{2 \mathrm{w}}\right)\right\}^{-1.376} \\
& \mathrm{v}_{\mathrm{hv}}=5.567 \times\left\{\mathrm{W}\left(\mathrm{q}_{\mathrm{cs}}\right)\right\}^{0.587} \times\left\{\mathrm{W}\left(\mathrm{q}_{\mathrm{cb}}\right)\right\}^{0.024} \times\left\{\mathrm{W}\left(\mathrm{q}_{\mathrm{hv}}\right)\right\}^{-0.114} \times\left\{\mathrm{W}\left(\mathrm{q}_{3 \mathrm{w}}\right)\right\}^{-0.461} \times \\
&\left\{\mathrm{W}\left(\mathrm{q}_{2 \mathrm{w}}\right)\right\}^{-1.351} \\
& \mathrm{v}_{3 \mathrm{w}}=4.347 \times\left\{\mathrm{W}\left(\mathrm{q}_{\mathrm{cs}}\right)\right\}^{0.222} \times\left\{\mathrm{W}\left(\mathrm{q}_{\mathrm{cb}}\right)\right\}^{-0.117} \times\left\{\mathrm{W}\left(\mathrm{q}_{\mathrm{hv}}\right)\right\}^{0.019} \times\left\{\mathrm{W}\left(\mathrm{q}_{3 \mathrm{w}}\right)\right\}^{-0.110} \times \\
&\left\{\mathrm{W}\left(\mathrm{q}_{2 \mathrm{w}}\right)\right\}^{-0.521} \\
& \mathrm{v}_{2 \mathrm{w}}=4.322 \times\left\{\mathrm{W}\left(\mathrm{q}_{\mathrm{cs}}\right)\right\}^{0.409} \times\left\{\mathrm{W}\left(\mathrm{q}_{\mathrm{cb}}\right)\right\}^{-0.056} \times\left\{\mathrm{W}\left(\mathrm{q}_{\mathrm{hv}}\right)\right\}^{0.030} \times\left\{\mathrm{W}\left(\mathrm{q}_{3 \mathrm{w}}\right)\right\}^{-0.138} \times \\
&\left\{\mathrm{W}\left(\mathrm{q}_{2 \mathrm{w}}\right)\right\}^{-0.654}
\end{aligned}
$$


b) Model B: Speed prediction models based on Underwood approach

$$
\begin{aligned}
& \mathrm{v}_{\mathrm{cs}}=4.741 \times\left\{\frac{\mathrm{q}_{\mathrm{cs}}}{\mathrm{w}\left(\mathrm{q}_{\mathrm{cs}}\right)}\right\}^{0.096} \times\left\{\frac{\mathrm{q}_{\mathrm{cb}}}{\mathrm{w}\left(\mathrm{q}_{\mathrm{cb}}\right)}\right\}^{-0.005} \times\left\{\frac{\mathrm{q}_{\mathrm{hv}}}{\mathrm{w}\left(\mathrm{q}_{\mathrm{hv}}\right)}\right\}^{-0.022} \times\left\{\frac{\mathrm{q}_{3 \mathrm{w}}}{\mathrm{W}\left(\mathrm{q}_{3 \mathrm{w}}\right)}\right\}^{-0.072} \times \\
& \left\{\frac{\mathrm{q}_{2 \mathrm{w}}}{\mathrm{W}\left(\mathrm{q}_{2 \mathrm{w}}\right)}\right\}^{-0.212} \\
& \mathrm{v}_{\mathrm{cb}}=4.914 \times\left\{\frac{\mathrm{q}_{\mathrm{cs}}}{\mathrm{W}\left(\mathrm{q}_{\mathrm{cs}}\right)}\right\}^{0.125} \times\left\{\frac{\mathrm{q}_{\mathrm{cb}}}{\mathrm{W}\left(\mathrm{q}_{\mathrm{cb}}\right)}\right\}^{0.011} \times\left\{\frac{\mathrm{q}_{\mathrm{hv}}}{\mathrm{W}\left(\mathrm{q}_{\mathrm{hv}}\right)}\right\}^{-0.051} \times\left\{\frac{\mathrm{q}_{3 \mathrm{w}}}{\mathrm{W}\left(\mathrm{q}_{3 \mathrm{w}}\right)}\right\}^{-0.072} \times \\
& \left\{\frac{\mathrm{q}_{2 \mathrm{w}}}{\mathrm{w}\left(\mathrm{q}_{2 \mathrm{w}}\right)}\right\}^{-0.270} \\
& \mathrm{v}_{\mathrm{hv}}=4.975 \times\left\{\frac{\mathrm{q}_{\mathrm{cs}}}{\mathrm{w}\left(\mathrm{q}_{\mathrm{cs}}\right)}\right\}^{0.122} \times\left\{\frac{\mathrm{q}_{\mathrm{cb}}}{\mathrm{w}\left(\mathrm{q}_{\mathrm{cb}}\right)}\right\}^{0.014} \times\left\{\frac{\mathrm{q}_{\mathrm{hv}}}{\mathrm{W}\left(\mathrm{q}_{\mathrm{hv}}\right)}\right\}^{-0.034} \times\left\{\frac{\mathrm{q}_{3 \mathrm{w}}}{\mathrm{w}\left(\mathrm{q}_{3 \mathrm{w}}\right)}\right\}^{-0.145} \times \\
& \left\{\frac{\mathrm{q}_{2 \mathrm{w}}}{\mathrm{W}\left(\mathrm{q}_{2 \mathrm{w}}\right)}\right\}^{-0.272} \\
& \mathrm{v}_{3 \mathrm{w}}=4.108 \times\left\{\frac{\mathrm{q}_{\mathrm{cs}}}{\mathrm{W}\left(\mathrm{q}_{\mathrm{cs}}\right)}\right\}^{0.046} \times\left\{\frac{\mathrm{q}_{\mathrm{cb}}}{\mathrm{W}\left(\mathrm{q}_{\mathrm{cb}}\right)}\right\}^{-0.032} \times\left\{\frac{\mathrm{q}_{\mathrm{hv}}}{\mathrm{W}\left(\mathrm{q}_{\mathrm{hv}}\right)}\right\}^{0.006} \times\left\{\frac{\mathrm{q}_{3 \mathrm{w}}}{\mathrm{w}\left(\mathrm{q}_{3 \mathrm{w}}\right)}\right\}^{-0.034} \times \\
& \left\{\frac{\mathrm{q}_{2 \mathrm{w}}}{\mathrm{w}\left(\mathrm{q}_{2 \mathrm{w}}\right)}\right\}^{-0.104} \\
& \mathrm{v}_{2 \mathrm{w}}=4.106 \times\left\{\frac{\mathrm{q}_{\mathrm{cs}}}{\mathrm{w}\left(\mathrm{q}_{\mathrm{cs}}\right)}\right\}^{0.084} \times\left\{\frac{\mathrm{q}_{\mathrm{cb}}}{\mathrm{w}\left(\mathrm{q}_{\mathrm{cb}}\right)}\right\}^{-0.011} \times\left\{\frac{\mathrm{q}_{\mathrm{hv}}}{\mathrm{w}\left(\mathrm{q}_{\mathrm{hv}}\right)}\right\}^{0.014} \times\left\{\frac{\mathrm{q}_{3 \mathrm{w}}}{\mathrm{w}\left(\mathrm{q}_{3 \mathrm{w}}\right)}\right\}^{-0.045} \times \\
& \left\{\frac{\mathrm{q}_{2 \mathrm{w}}}{\mathrm{w}\left(\mathrm{q}_{2 \mathrm{w}}\right)}\right\}^{-0.131}
\end{aligned}
$$

\subsection{Validation of speed models}

In order to check the accuracy, the speed models developed were validated using the field data which were kept aside for this purpose. Predicted speeds by the models based on the observed classified volumes were compared with the observed speeds. Fig. 2 depicts the validation plots for small car and big car category. As it may be seen, Model B i.e. the models based on Underwood approach performed better in predicting speed even for each vehicle category compared to Model A. Similar results were obtained for other three vehicle categories also. Measures of accuracy in predicting speed by these models are given in Table 2. Average $\mathrm{R}^{2}$ and Root Mean Square Error (RMSE) for Model B were respectively observed as 0.79 and 0.43 while Model A yielded a comparative lower $\mathrm{R}^{2}$ and a higher RMSE of 0.63 and 0.60 respectively. Thus, the present study finds Underwood approach based speed models (eqns (27)-(31) capable of predicting speed with a fair accuracy and suggests the same for speed prediction on two lane road in the context of urban mixed traffic.

Table 2: Measures of accuracy for Model A and Model B.

\begin{tabular}{|c|c|c|c|c|}
\hline \multirow{2}{*}{ Vehicle Type } & \multicolumn{2}{|c|}{ R2 } & \multicolumn{2}{c|}{ RMSE } \\
\cline { 2 - 5 } & Model A & Model B & Model A & Model B \\
\hline CS & 0.57 & 0.86 & 0.70 & 0.40 \\
\hline CB & 0.69 & 0.79 & 0.67 & 0.55 \\
\hline HV & 0.56 & 0.82 & 0.82 & 0.52 \\
\hline 3W & 0.70 & 0.74 & 0.40 & 0.37 \\
\hline 2W & 0.63 & 0.74 & 0.39 & 0.33 \\
\hline Average & 0.63 & 0.79 & 0.60 & 0.43 \\
\hline
\end{tabular}




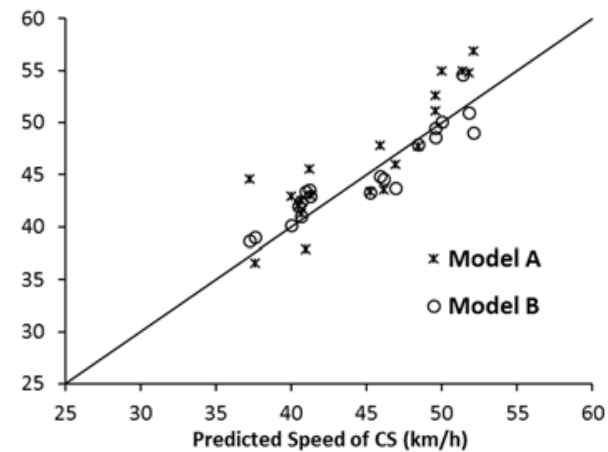

(a)

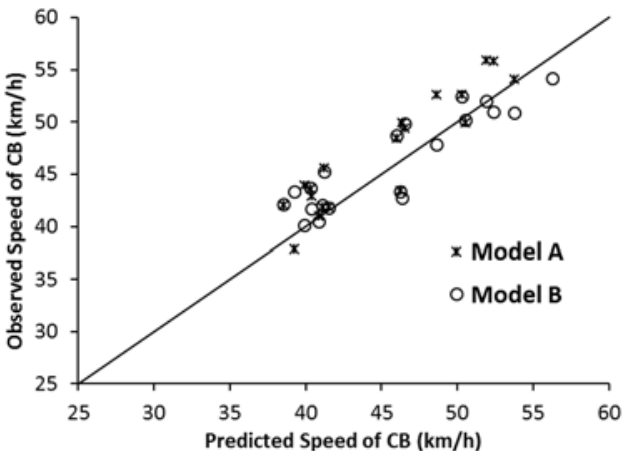

(b)

Figure 2: Observed and predicted speeds for (a) CS and (b) CB.

\subsection{Estimation of speed and PCU}

Using eqns (27)-(31), average speeds for five categories of vehicle were estimated against the given classified volumes. The speeds predicted by the proposed model were used in eqn (19) to estimate PCU of a vehicle type. The individual rectangular areas required for PCU estimation were taken from Table 1. It is needless to mention that both of speed and PCU vary with the traffic circumstances. Therefore, for better understanding how these speeds and PCU change with the change in traffic conditions, a sensitivity analysis was performed.

\section{SENSITIVITY ANALYSIS}

\subsection{Influence of traffic volume on speed}

Total volume (veh/h) was varied within the observed range keeping the composition constant at its overall observed values and corresponding speeds were estimated using the model (eqns (27)-(31)) suggested. Speed irrespective of vehicle categories was observed declining with the increase in volume as shown in Fig. 3. However, the rate of declination differs depending upon the vehicle category. Heavy vehicle being large in size faces more resistance with the increase in total volume and rapidly lose its mobility resulting in a high reduction rate of speed. On the other hand, average speeds of two-wheeler and three-wheeler do not get reduced as much as compared to the other categories. This is because of their smaller sizes and higher manoeuvring capabilities even at an increased volume condition. Small cars and big cars have almost similar speed trend. However, big cars have a marginally higher reduction rate in speed due to its larger size.

\subsection{Influence of traffic composition on speed}

Traffic volume was fixed at a defined value $2500 \mathrm{veh} / \mathrm{h}$. Then, the traffic composition was varied in a complementary manner and corresponding changes in individual speed were studied as shown in Fig. 4. Increase in the proportion of heavy vehicles in the traffic stream results in a speed drop for all the vehicles on a two-lane undivided road. It is due to its bigger size and poor operating characteristics at increased volume condition. Two wheelers on the other hand, are small sized and also have good manoeuvrability even at high traffic volume 


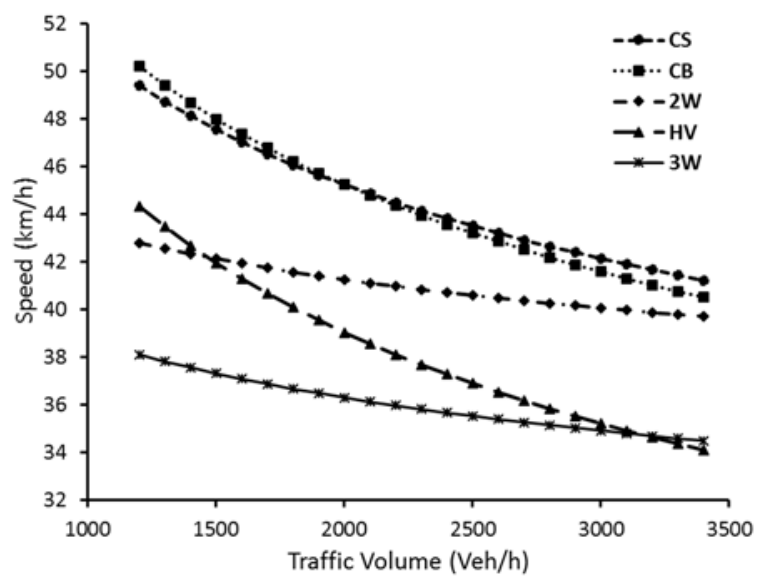

Figure 3: Effect of traffic volume on average speed of different vehicle types at a composition of CS 40\%, CB 10\%, HV 5\%, 3W $5 \%$, $2 \mathrm{~W} 40 \%$.

condition. Thus, the increase in the proportion of two wheelers results in a less space occupancy on the road and speed of the individual vehicles increases.

\subsection{Influence of traffic volume on PCU}

In order to study the dynamics of PCU, total volume was varied within the observed range keeping the composition constant at its overall observed values and corresponding PCU for each category of vehicle was estimated using eqn (15). As may be seen in Fig. 5, PCU of big car and heavy vehicle increases with the increase in total volume while it decreases for the other two categories. This is owing to the fact that big cars and heavy vehicles have higher reduction rate in speed compared to small car (standard vehicle in this study) as discussed previously. Thus, the PCU which refers to the relative speed of these two vehicle types, was observed increasing with the increase in total volume. Oppositely, two-wheeler and threewheeler are the categories which have a lower reduction rate in speed compared to that of a small car. As a result, PCU of these categories drops with the increase in the total volume.

\subsection{Influence of traffic composition on PCU}

In order to study the influence of traffic composition on individual PCU, traffic volume was fixed at $2500 \mathrm{veh} / \mathrm{h}$. Traffic composition was varied in a complementary manner and resulted speeds were utilized in eqn (19) to estimate PCU for different vehicle types (Fig. 6).

PCE of two-wheelers and three wheelers decreases with the increase in the proportion of heavy vehicles in the traffic stream, however it increases for other vehicle types. Two wheelers and three wheelers experience less resistance compared to small cars with an increased space occupancy condition on the road caused by the rise in the proportion of heavy vehicles in the traffic stream. On the contrary, big cars and heavy vehicles due to their larger size or poor operational characteristics, experience more resistance with the aforementioned traffic situation. However, when the proportion of two wheelers increases in the traffic stream, the opposite trend was observed as PCE of two wheelers and three wheelers increases while it decreases for other vehicle types. 


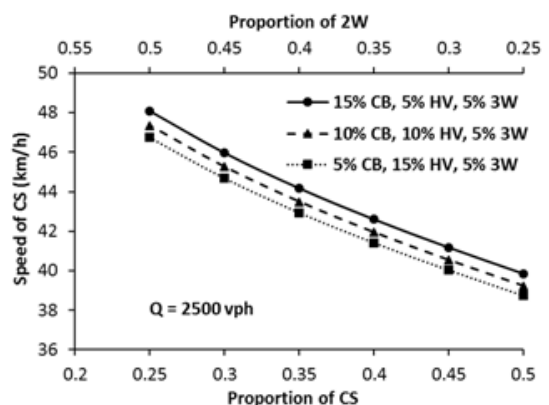

(a)

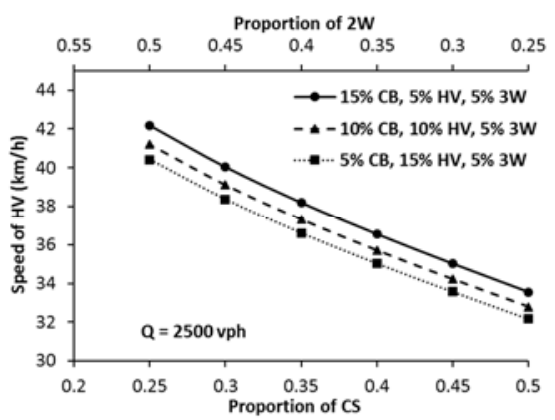

(c)

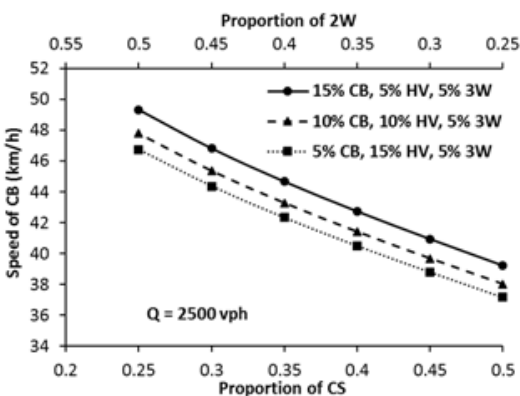

(b)

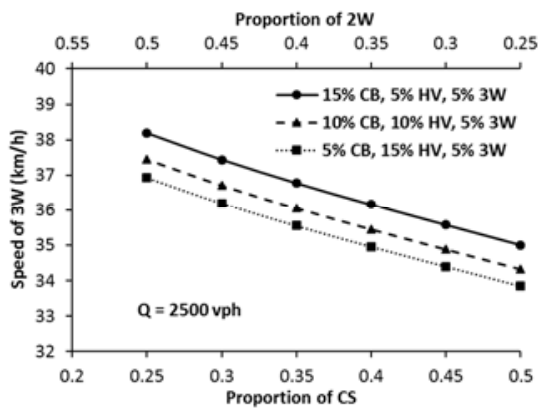

(d)

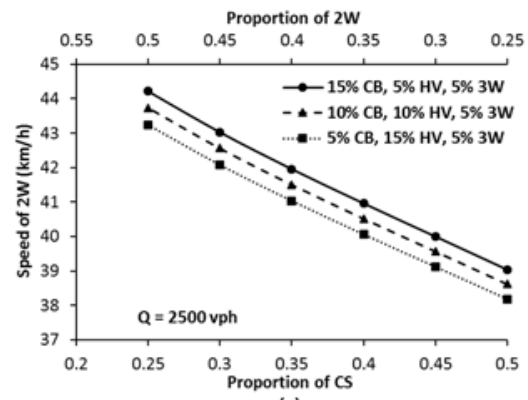

(e)

Figure 4: Effect of traffic composition on average speed of (a) CS, (b) CB, (c) HV, (d) $3 \mathrm{~W}$ and (e) $2 \mathrm{~W}$.
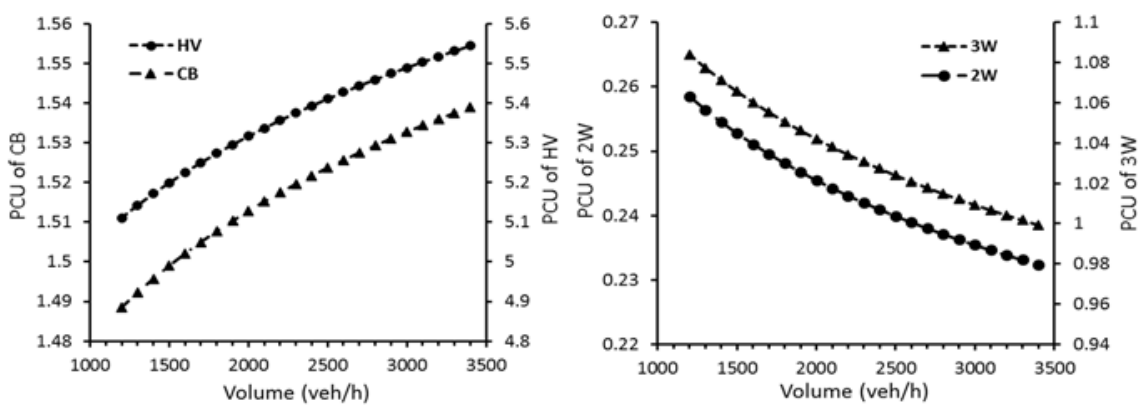

Figure 5: Effect of traffic volume on PCU for different vehicle types at a composition of CS $40 \%$, CB 10\%, HV 5\%, 3W 5\%, 2W 40\%. 


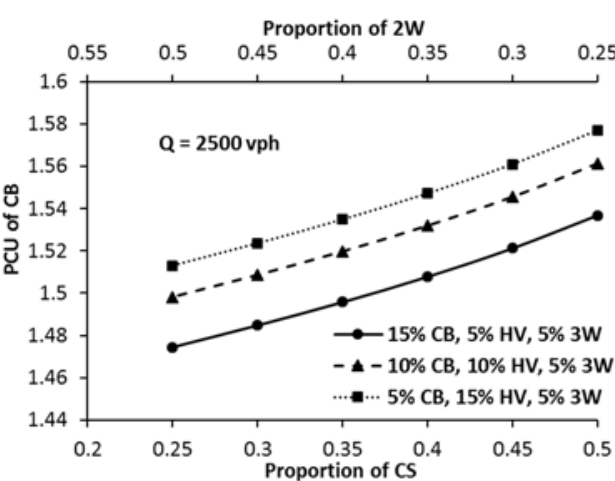

(a)

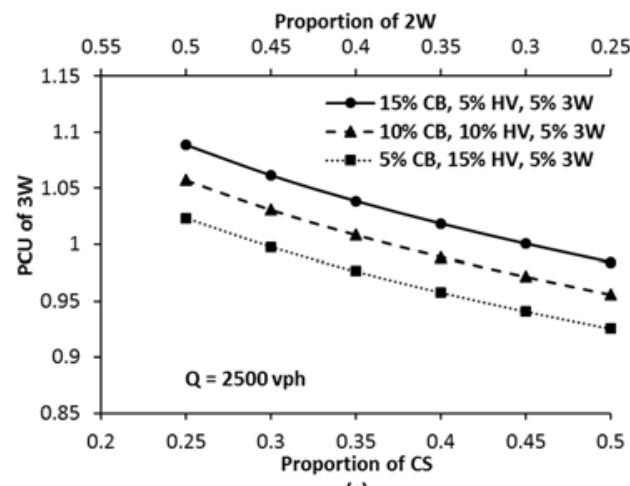

(c)

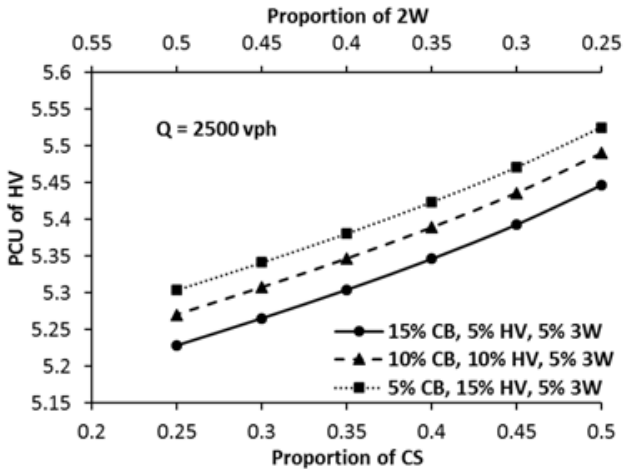

(b)

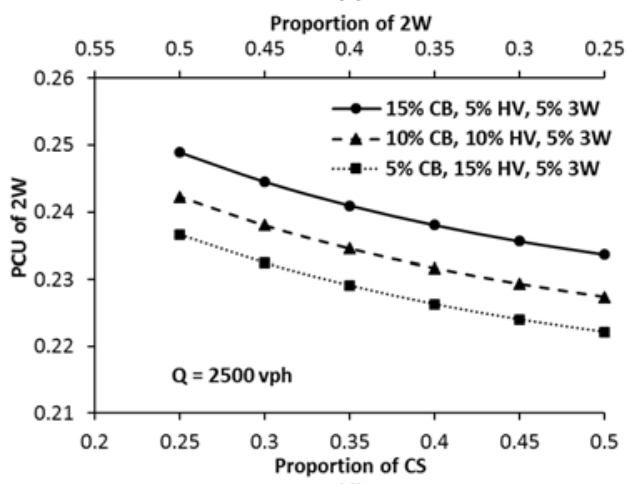

(d)

Figure 6: Effect of traffic composition on PCU of (a) CB, (b) HV, (c) $3 \mathrm{~W}$ and (d) $2 \mathrm{~W}$.

\section{CONCLUSION}

This paper has forwarded a semi-analytical approach for estimation of speed and PCU of a vehicle category. Principal branch of Lambert $\mathrm{W}$ function has been utilized in formulating speed models. Two groups of macroscopic speed models have been derived from two existing theories in macroscopic traffic flow modelling namely, Greenberg and Underwood model. However, the study has found the Underwood based speed model more efficient as the speeds obtained by this model are observed in a better agreement with the observed speed data. Developed speed models are also compatible to mixed traffic conditions and can predict individual influences of different vehicle categories present in the traffic stream. The major findings of this study are summarized below:

1. For the same composition in the traffic stream, increase in total volume causes a prominent reduction in speed. However, the extent of the influence differs depending upon the category of vehicle. Small sized vehicles like two-wheeler and threewheeler have lower reduction rates compared to other categories whereas a stiff reduction in speed have been observed for larger sized vehicles like big car and heavy vehicle.

2. Traffic volume has a significant impact on PCU of different vehicle categories. PCU of larger sized vehicles increases with the increase in traffic volume for the same 
composition in the traffic stream. Whereas, it decreases for small sized vehicles due to their better manoeuvring capability.

3. Individual speed and PCU were observed varying depending upon the composition in traffic stream. A reduction in speed was invariably observed as a result of the increase in heavy vehicle proportion. However, in case of PCU, the nature of this influence depends on the subject vehicle category. PCU of larger sized vehicles increases with the increase in heavy vehicles in the traffic stream while it decreases for a small sized vehicle like two wheelers and three wheelers.

4. Models suggested in this paper can be useful in predicting speed on a two lane undivided urban road carrying heterogeneous traffic. However, in context of other countries where vehicular characteristics differ significantly from the case considered in this study, this paper can be handled as a guideline to develop speed model's compatible with the changed conditions. As a further scope, this study also can be extended to other road categories carrying heterogeneous traffic.

5. One limitation associated with the models proposed in this paper is that the volume for each individual category has to be non-zero. Because, W(q) cannot be computed when $\mathrm{q}$ tends to zero. Also, the applicability of these models are limited to uncongested conditions. Congested flow could not be addressed due to limitation of the field data.

\section{APPENDIX: FINDING THE ROOT OF EQUATION 16}

Let us consider a new variable $\mathrm{z}$ such that

$$
\mathrm{z}=\ln \mathrm{x}
$$

Therefore:

$$
\mathrm{y}=\mathrm{z} \mathrm{e}^{\mathrm{z}}
$$

Based on eqn (1) and eqn (2):

$$
\mathrm{z}=\mathrm{W}(\mathrm{y})
$$

From eqn (16):

$$
x=\frac{y}{\ln x}
$$

Therefore:

$$
\mathrm{x}=\frac{\mathrm{y}}{\mathrm{W}(\mathrm{y})}
$$

\section{REFERENCES}

[1] Tefft, B. C., Impact speed and a pedestrian's risk of severe injury or death. Accid. Anal. Prev., 50(1), pp. 871-878, 2013.

[2] Sun, Z., Hao, P., Jeff, X. \& Yang, D., Trajectory-based vehicle energy/emissions estimation for signalized arterials using mobile sensing data. Transp. Res. Part D, 34(1), pp. 27-40, 2015.

[3] Maitra, B., Sikdar, P. K. \& Dhingra, S. L., Modeling congestion on urban roads and assessing level of service. J. Transp. Eng. ASCE, 125(6), pp. 508-514, 1999.

[4] Fitzpatrick, K., Carlson, P., Brewer, M. \& Wooldridge, M., Design factors that affect driver speed on suburban streets. Transp. Res. Rec. J. Transp. Res. Board, 1751, 012163, pp. 18-25, 2001. 
[5] Tsapakis, I., Cheng, T. \& Bolbol, A., Impact of weather conditions on macroscopic urban travel times. J. Transp. Geogr., 28, pp. 204-211, 2013.

[6] Chiguma, M. L. M., Analysis of side friction impact on urban road links; case study Dar-es-salaam. Royal Institute of Technology Stockholm, Sweden, 2007.

[7] Greenberg, H., An analysis of traffic flow. Oper. Res., 7(1), pp. 79-85, 1959.

[8] Underwood, R. T., Speed, volume, and density relationships. Yale Bur. Highw. Traffic, pp. 141-188, 1961.

[9] Tranportation Research Board, Highway Capacity Manual. Washington D.C., 1965.

[10] Fan, H. S. L., Passenger car equivalents for vehicles on Singapore expressways. Transp. Res. Part A Gen., 24(5), pp. 391-396, 1990.

[11] Chandra, S. \& Kumar, U., Effect of lane width on capacity under mixed traffic conditions in India. J. Transp. Eng. ASCE, 129(2), pp. 155-160, 2003.

[12] Cao, N. Y. \& Sano, K., Estimating capacity and motorcycle equivalent units on urban roads in Hanoi, Vietnam. J. Transp. Eng. ASCE, 138(6), pp. 776-785, 2012.

[13] Euler, L., De formulis exponentialibus replicatis. Opera Math., 15, pp. 268-297, 1927.

[14] Arasan, V. T. \& Arkatkar, S. S., Microsimulation Study of Effect of Volume and Road Width on PCU of Vehicles under Heterogeneous Traffic. J. Transp. Eng. ASCE, 136(12), pp. 1110-1119, 2010.

[15] Basu, D., Maitra, S. R. \& Maitra, B. Modelling passenger car equivalency at an urban mid- block using stream speed as measure of equivalence. Eur. Transp., 34, pp. 7587, 2006. 